\title{
The challenges and opportunities of adopting artificial intelligence (AI) in Jordan's healthcare transformation
}

Shakir Karim *, Central Queensland University, School of Engineering and Technology, Australia, Jordan

Raj Sandu, Central Queensland University School of Engineering and Technology, Australia,Jordan

Mahesh Kayastha, Central Queensland University ,School of Engineering and Technology , Australia, Jordan

\section{Suggested Citation:}

Karim, S., Sandu, R., \& Kayastha, M. (2021). The Challenges and Opportunities of Adopting Artificial Intelligence (AI) in Jordan's Healthcare transformation. Global Journal of Information Technology: Emerging Technologies. 11(2), 35-46.: https://doi.org/10.18844/gjit.v11i2.6546

Received from June 30,2021; revised Augsut 11,2021; accepted October 27,2021.

Selection and peer review under responsibility of Asist. Prof. Dr. Ezgi Pelin YILDIZ, Kafkas University, Turkey. 2021 Birlesik Dunya Yenilik Arastirma ve Yayincilik Merkezi, Lefkosa, Cyprus.

\begin{abstract}
Artificial Intelligence ( $\mathrm{Al}$ ) is the greatest development and promise in the present technology world, as it promises big contribution, massive changes, modernization, and coordination with and within people's progressing life. This paper aims to provide an analysis of Jordan health care that are co-connected and interconnected with the consequences formed by Artificial Intelligence (Al) and focuses on the strengths and weaknesses of adopting $\mathrm{Al}$ in health sector. It also discusses the local awareness and familiarization of Artificial Intelligence (Al) in Jordan healthcare providers and gives a consistent assessment of current and future best practices. Data was gathered by using interviews from Jordan IT and health care providers. The investigation found that $\mathrm{Al}$ is consistently changing the way healthcare is to be directed in Jordan. Al can provide solid healthcare services to the stakeholders. As a developing country, Jordan has not fully adopted Artificial Intelligence (Al) in its healthbsector.
\end{abstract}

Keywords: Artificial Intelligence (AI); Challenges; Health care System; Jordan; Opportunities

* ADDRESS FOR CORRESPONDENCE: School of Engineering and Technology Central Queensland University, Australia Jordan E-mail address: s.karim@cqu.edu.au 


\section{Introduction}

Seeing the development of a field that is going to affect the wellbeing industry and the life of billions of individuals is interesting. Artificial Intelligence (Al), as opposed to Natural (human) Intelligence, will be an insight exhibited by machines. Computer based intelligence additionally called Machine Intelligence, intends to copy human insight by having the option to secure and apply information and abilities (Shortliffe, 2012). Al has proven itself capable of improving process efficiency, reducing human errors and labour, and extracting insights from data (Mitchell, Michalski, and Carbonell , 2013).

\subsection{Literature Review}

This part provides the basic and obtainable understanding of $\mathrm{Al}$ ) in transforming healthcare in Jordan, overall impact of Al, opportunities, and satisfaction.

\section{Figure 1}

Map of Jordan

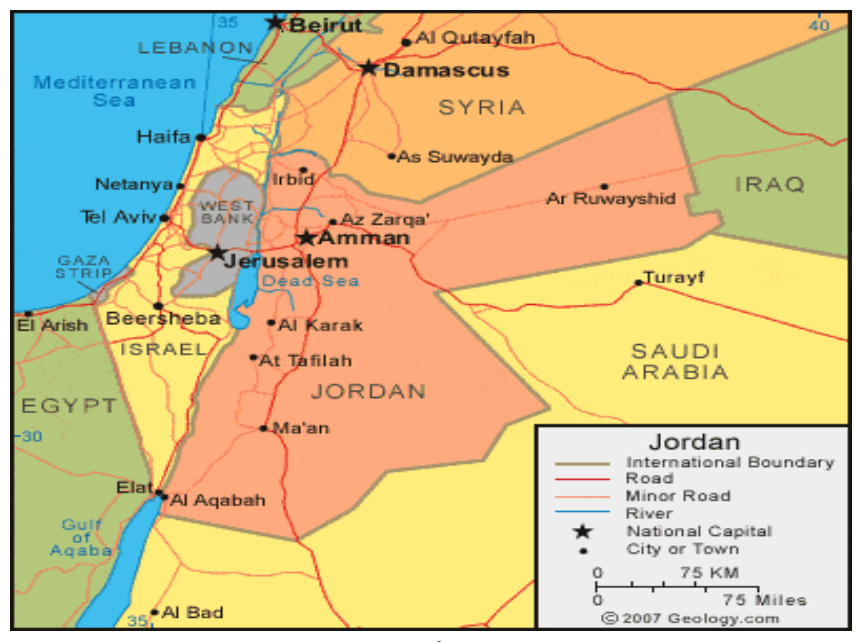

Source: Robins, 2019

\section{Table 1}

Overview of an Arabic country: Jordan-2020

\begin{tabular}{|c|c|c|}
\hline $\begin{array}{l}\text { Country: Jordan } \\
\text { Official Name: Al-Mamlakah al- } \\
\text { Urduniyyah al-Hāshimiyyah } \\
\text { (Hashemite Kingdom of Jordan) }\end{array}$ & Capital: Amman & $\begin{array}{l}\text { Economic: } \\
\text { Agriculture, } \\
\text { Industry, } \\
\text { Services }\end{array}$ \\
\hline $\begin{array}{l}\text { GNI (U.S.\$'000,000) (2017) 38,660 } \\
\text { GNI Per Capita (U.S.\$) (2017) 3,980 }\end{array}$ & $\begin{array}{l}\text { Currency: } \\
\text { Jordanian Dinar (JD) }\end{array}$ & $\begin{array}{l}\text { Political system: Constitutional } \\
\text { monarchy }\end{array}$ \\
\hline $\begin{array}{l}\text { Religion: Muslim } \\
(97.2 \%) \\
\text { Orthodox } \\
\text { Christians }(1.4 \%)\end{array}$ & $\begin{array}{l}\text { Population: (2020 est.) } \\
\text { 10,679,000, Population Rank } \\
\text { (2019) 88, Population } \\
\text { Projection } 2030 \text { 11,936,000 }\end{array}$ & $\begin{array}{l}\text { Urban-Rural Population } \\
\text { Urban: (2017) 90.3\% } \\
\text { Rural: (2017) 9.7\% }\end{array}$ \\
\hline Language: Arabic & Land Area: 88,794 SQ KM & $\begin{array}{l}\text { Approximate Flight Time: } \\
\text { (HKG-AMM): } 13 \text { hours } 50 \text { minutes }\end{array}$ \\
\hline
\end{tabular}

Source: Robins, 2019 
Figure 1 and table 1 show, Jordan officially the Hashemite Kingdom of Jordan is an Arab country in Western Asia, on the East Bank of the Jordan River. Jordan is bordered by Saudi Arabia to the south, Iraq to the north-east, Syria to the north and Israel and Palestine (West Bank) to the west (Robins, 2019).

The Jordan government can provide an example in using Al services in health care sector to reduce costs, lift productivity, efficiency, utilisation and develop better healthcare services. In addition, healthcare service providers can use Al for offering best healthcare support and when replacing any existing physical services because it is the best option for the purpose, offer the best value for quality and provide adequate health risk (Mohammad, Almarabeh \& Ali, 2009). The below section provides further understanding of $\mathrm{Al}$ in health.

\subsubsection{Introduction to Artificial Intelligence (AI)}

Naomi Simson, Entrepreneur of Big Red Group (BRG) says "Artificial Intelligence (Al), is a term first coined by John McCarthy in 1956 when he invited a group of researchers to the Dartmouth Summer Research Project workshop to discuss what would ultimately become the field of Al (Karim, Sandu, \& Gide, 2020). According to The Encyclopedia Britannica, "Artificial Intelligence (AI) today is the ability of a digital computer or computer-controlled robot to perform tasks commonly associated with intelligent beings." Intelligent beings are those that can adapt to changing circumstances (Karim, Sandu, \& Gide, 2020).

\subsubsection{How Al is Beating Disease - Prostate Cancer}

Very minimum health care providers in Jordan offer a computerised support which streamlines the evaluation and finding of sicknesses, such as - prostate cancer, using Al innovation tailored to clinicians and patients. Its online platform analyses clinical information, including medical imaging, blood data, to deal with the danger of prostate cancer. It expects to decrease the expense of prostate cancer testing and treatment and analyse the disease as early as possible (Karim, Sandu, \& Gide, 2020). Professor Elliot Smith said, "We use Al to analyse all the data that they have and any data that comes in the future through testing process, and using that, we can give them accurate screening or diagnosis." Professor Elliot Smith also said, "The Al can read more into the data than a physician usually would (Karim, Sandu, \& Gide, 2020)."

Smith Baxter (2019) said in using Al, "All these things come together to give a very personalised and very in-depth picture of risk of prostate cancer. That will be paired with a clinician who would see the output from the Al, review that and communicate to you through the platform about what current risk is and what the recommended next step is." "It's a long process and there's a lot of paperwork involved but if you're doing the right things and building a quality piece of technology, and employing the highquality engineering practices, then it's not that hard (Karim, Sandu, \& Gide, 2020)."

"Al and clinicians can together manage the risk of a number of high-risk diseases, and if any diseases are to pop up, it is known far enough in advance to have the best treatment options and for them to stop becoming life-threatening," Smith said. While a central concern around Al technology is that it can replace humans, leading to job losses and ethical quandaries, but can produce the best result for the patient. Al is an incredible apparatus to expand the capacity of current clinicians to get them there, yet it's far from debilitating the stock of clinicians (Karim, Sandu, \& Gide, 2020).

\subsubsection{Artificial Intelligence (Al) In Jordan Healthcare}


In respect to $\mathrm{Al}$ impact challenge for a translational computerized wellbeing program that will utilize advanced devices to counteract episodes. In realistic practice, Jordan is now data rich, but information poor (Bani-Salameh, Al-Amanah and Taamneh, 2021). Currently Jordan has different health care systems for the private and public sectors. The 'Hakeem' health program (e-health solution) is adopted by public health sectors where the health data from over five million patients have been collected and stored in an electronic format. The multi-systems are used by the private sectors and computerized (Bani-Salameh, Al-Qawaqneh and Taamneh, 2021). There are different types of data such as structured (e.g., laboratory tests), semi-structured (e.g. electronic health and medical records and instrument reading and unstructured (e.g. handwritten nurse notes, medical images, videos, electrocardiogram (ECG) etc) (Bani-Salameh, Al-Qawaqneh and Taamneh, 2021).

As an example, the computerised health program can convey custom fitted guidance and pokes utilizing Al to members who have displayed at medical clinic with chest torment, bridling their advanced impression to decrease the danger of a coronary episode (Karim, Sandu, \& Gide, 2020). By consolidating clinical and shopper inferred information, for example, from cell phone applications and wearables, with $\mathrm{Al}$, it is accepted the precision of hazard evaluation will be improved while making progressively versatile computerized health arrangements (Yu, Beam, \& Kohane, 2018).

University of Sydney, Australia Vice-Chancellor Dr Michael Spence said, "Al has the potential to transform health care globally - from crisis management to prevention - and people are delighted to be working with industry and with government to look at new ways of tackling society's growing health burden (Karim, Sandu, \& Gide, 2020)." Federal Minister Andrews said: "Al is the perfect example of how technology, combined with human know-how, can deliver incredible benefits (Karim, Sandu, \& Gide, 2020)."

Health framework in Jordan develops quick, and it includes huge and varying sensitive data. But still it needs to be stored, arranged, managed, and analyse efficiently and with productivity which Al can only do that (Bani-Salameh, Al-Qawaqneh and Taamneh, 2021). Al gathers valuable health data and get insights from the raw data. It focuses on how to analyse the data that could not be handled using the basic investigation methods, because of their volume, velocity, and the other data characteristics (Karim, Sandu, \& Gide, 2020). It can focus on how to analyse raw data collected from medical centres to get insights and use it to offer better medical care (Karim, Sandu, \& Gide, 2020).

"Jordan health sector are eventually starting to come off the peak of the hype cycle regarding impact of Al and Digital Health. There was a definite focus on implementation of perhaps less blue sky but more immediately practical solutions to improve functioning and efficiency of healthcare delivery using Al to reduce unnecessary readmissions," said by a health expert in Jordan (Bani-Salameh, Al-Qawaqneh and Taamneh, 2021). There was much talk about the need to capture social determinants of health data and integrate this into managing health. Interestingly there was talk about the failure of many small $\mathrm{Al}$ companies and the need for consolidation (Al-Hawary, 2012).

\subsubsection{Al Tool Can Predict and Work Equally for Patients}

The technology facilities, communication field in Jordan, have meaningly improved within last few years including city and countryside areas. A social media expert expressed to The Jordan Times "The encouragement both from government and public sectors has encouraged this sector significantly" 
(Pakurár, 2019). "The availability of smart devices in Jordan has significantly increased the number of social media users and this trend is expected to continue to grow," a social media expert told to the Jordan Times (Al-Alami, Hadi, \& Al-Bahadili, 2017).

Multiple Science and Health Lab has developed a new deep learning-based Al prediction model that can anticipate the development of breast cancer up to five years in advance. The Researchers who are comprehensively working on the product also recognized that other similar projects have often had inherent bias because they were based overwhelmingly on specific patient populations, and specifically designed their own model so that it is informed by "more equitable" data that ensures it's "equally accurate for multicultural women (Karim, Sandu, \& Gide, 2020)." The Al project can help Jordan healthcare professionals put together the right screening program for individuals in their care and eliminate the common outcome of late diagnosis. The technique can also be used to improve detection of other diseases that have similar problems with existing risk models with far too many gaps and lower degrees of accuracy (Karim, Sandu, \& Gide, 2020).

Using $\mathrm{Al}$ in health shows promise, but only when it comes to supporting patients with repetitive and predictable tasks. According to the author (Murphy, 2019) "Good treatment is complex and requires creativity, flexibility, improvisation and spontaneity". He also has mentioned "Doctors need the abilities to think logically and apply common sense, compassion and empathy to deal with the everyday nonacademic issues and problems that arise in the workplace." Al can help to simulate human perception and decision-making, can solve novel problems without having preprogramed knowledge of the task to be performed (Karim, Sandu, \& Gide, 2020).

\subsubsection{How will Al Help Prevent Heart Attacks}

Al connecting with health services can transform medical care for populations because they lead to earlier identification of at-risk individuals, enable better access prioritisation based on risk, and monitoring intensity based on individual risk (Karim, Sandu, \& Gide, 2020). A cardiologist from the university of Sydney, Australia said: "Al could harness data to create digital health programs which allow greater efficiency in health care delivery (Karim, Sandu, \& Gide, 2020)."

\subsubsection{Al's Hardest Problem? Developing Common Sense}

This is just a short statement that reflects the difference between humans and Al systems (HernándezOrallo \& Vold, 2019). Humans are great at guessing or just creative thinking. How do humans do this, is it linked to the unconscious mind and use of memory. The problem for Al is to mimic or copy the way humans use data and the environment to decide what to do or not do. Humans make errors or incorrect decisions, but they can realize and correct the problem and learn from the experience. How can you build rules/algorithms for a machine to act and think like a human? If that is what you want to do with $\mathrm{Al}$, this is not the goal (Leslie, 2019)?

\subsubsection{Barriers of Artificial Intelligence (Al) in Jordan Healthcare Services}

Hardware and software' high price, websites' less access, poor IT infrastructure, inadequate IT personnel, Mismanagement of technology, poor law practice, poor security control, untrustworthy, absence of law's best practices, poor confidence on benefits of Al, lacking of strong commitments from 
government and non-government parties, unsatisfactory number of skilled employees in health sector (Abdel-Razeq, Attiga \& Mansour, 2015), all are considered as potential barriers.

There are some common cybercrimes existing in Jordan such as hacking, Denial of Service (DoS) Attack, computer virus, software piracy, spamming, phishing (Ishaqat, 2021) unauthorised copying, extracting, and downloading of data, damage to system and network etc. (Ishaqat, 2021). In addition, Hakeem's internal policies require official approaches and top management involvement to facilitate the integration of Al with their system (Bani-Salameh, Al-Qawaqneh and Taamneh, 2021). Dealing with sensitive data, which requires a huge effort to convince the stakeholders of the capability of Al and the high level of security that ensures and maintains data privacy (Bani-Salameh, Al-Qawaqneh and Taamneh, 2021).

\subsection{Scope of the research}

This research focuses majority on the healthcare in Jordan. This research also focuses on Jordan healthcare providers such as hospitals, medical centres, doctors, physicians, nurses, pharmacists etc. Jordan is an emerging country with solid future for growth in Artificial Intelligence (AI) field. If Jordanians and healthcare enterprises are satisfied with Artificial Intelligence (AI):

- Majority people will be in the range of facilitation of Al in transforming Jordan healthcare system.

- Potential Jordanians will understand about the Artificial Intelligence (AI) in healthcare.

- Al prompts having a competitive business advantage in public wide or worldwide.

- The health workforce in Jordan will understand health related issues with Al, legislation related issues, so they will contribute more on healthcare sector.

- Al will assist stakeholders to gain productivity and assists to lead the day-to-day life more conveniently (Barr \& Feigenbaum, 2014).

The objectives are identified as per below:

- Delivering a clear vision of $\mathrm{Al}$ in transforming healthcare system in Jordan.

- Identifying the existence of Al and illustrate its appropriate presence and justification in Jordan medical services.

- Finding the past and present standing of Artificial Intelligence (AI) in Jordan healthcare system.

- Finding out the background of ICT industry, Al technology, Artificial Intelligence (AI) challenges \& opportunities and business under health significance in Jordan Healthcare.

- Recognising advantages and disadvantages of Artificial Intelligence (Al) in transforming healthcare in Jordan.

- Offering all the stakeholders in health sector, a complete awareness of Al operations in Jordan.

- Performing an effective and efficient valuation of Al for healthcare system in Jordan.

- Categorizing common factors for customer and business satisfaction by using of Artificial Intelligence (AI) in Jordan Healthcare health sector.

- Analysing economic, legal, social, ethical, and political issues in the context of Al in Jordan Healthcare health.

- Learning how Artificial Intelligence (AI) can help in the overall development in health sector (Goodman, Zandi, Reis \& Vayena, 2020).

This paper answers the following key Questions about Artificial Intelligence (Al) and Jordan healthcare:

- What is the past and present status of Al in Jordan? 
- How Artificial Intelligence (AI) in healthcare leads to having a competitive advantage in the different levels particularly in Jordan?

- How could Jordan build up the opportunity to develop satisfaction in Al for its own health sector growth?

- Are health consumers fully informed about the status of their health, their healthcare choices and the cost and quality of services and products in the Jordan health market?

- Are healthcare service providers sufficiently informed to provide appropriate and continuous health care to each Jordanian?

- Do policy makers have a complete picture of consumers' health data, the cost and quality of healthcare, and probable future health market demand patterns to make informed decisions in Jordan?

- How the rapidity of Artificial Intelligence (Al) affect customer satisfaction in Jordan health industry?

- Does reliability of Artificial Intelligence (Al) effect clients' fulfilment in Jordan health area?

\subsection{Purpose of Research}

The aim of this paper is to identify and assess the key factors that can assist in clear understanding of levels of Jordanian health industry and impact of Al. In addition, it aims to improve complete rely on Al for health care sector in Jordan.

\subsection{Significance of the Study}

This study is very vital for Jordan individuals and to be able to acknowledge technology acceptance decision in Jordan and furthermore huge in anticipating a customer's objective to embrace Al in heath industry. In addition,

- $\mathrm{Al}$ is the vital trend for health institutions to keep track of. Al is and will be more frequent regular practice in the computer world.

- A using in a health framework is the most developed pattern and the cutting-edge competitive business advantage in the Jordan health industry (Zaid Alkilani, Jupp \& Sawhney, 2013).

\section{Materials and Methods}

This study took on a qualitative research method based on interview process. It also included the analysis of interviews. The chosen qualitative approach provides a huge amount of information. It starts reviewing published secondary resources related with the topic, identifies Al satisfaction and possible solutions. In this paper, the researchers compare between the previous and current status of the research study. In addition, the researchers have communicated with some government and nongovernment organizations to get data. The researchers also have accessed to some learning and education hub to get some statistics and publications.

\subsection{Participants}

The interviews are conducted to collect significant data from ICT sector, Al and cyber security experts, Jordanian Government and non-Government officials, ICT educators and learners, university academics and potential students etc.

The key interview people are informed by email. The researchers have approached them with proper consents and received positive responses. The academics have communicated with the students to become volunteer and to get the responses. The researchers have also contacted the Faculty by sending 
an invitation letter to get the most appropriate students. Thirty-five potential students have been selected in this occasion.

\subsection{Data Analysis}

The interview sessions have taken half an hour per session. Interviews have been recorded digitally. iPad, digital audio recorder and laptop have been used as electronic devices and Skype, Viber \& WhatsApp have been used as applications. All data have been sorted and analysed. Qualitative data analysis with relevant computer software (NVivo) have been used. The researchers have categorised all the transcripts into alphabetical order of interviewees' Surname. Also, the researcher has prioritised the highest contributors.

\subsection{Research Procedure}

The outcomes have been developed from the key interviewers such as ICT and health expertsidentified by $11,12,13,14,15$, the Government and non-Government officials- identified by G1, G2, G3, G4, G5, Academics-identified by A1, A2, A3, A4, A5 and Students identified by S1, S2, S3, S4, S5. The interview data mainly about Artificial Intelligence's (Al) impact in Jordan Healthcare are subject to the process of analysis resulting in the below vital key issues: the impact of secured Al in Jordan Healthcare, the main reasons contribute strongly for the non-operation of Al in the past in Jordan Healthcare, business restrictions exist in the development of Al in Jordan Healthcare, Jordan Healthcare consumers' concerns about Al, economically importance about Al to Jordan Healthcare, the economic impact of Al on business costs and productivity and facilitates the development of business of Jordan Healthcare, the current situation of network infrastructure in Jordan Healthcare, industrial solutions to give consumers confidence about security in Al, the role of the private sector and the public sector in developing $\mathrm{Al}$ and Jordan Healthcare enterprises' role to make fast and easy going healthcare services between the stakeholders (Bani-Salameh, Al-Qawaqneh and Taamneh, 2021).

\section{Results and Discussion}

As $\mathrm{Al}$ is promptly increasing in Jordan, although $\mathrm{Al}$ is considered noteworthy intelligence demonstrated by machines for the development to the Jordan health sector. This below section has provided some key findings:

- Al have emerging business potentials in Jordan healthcare system, but some poor decision makings are the basic reasons behind the lag of Al in Jordan healthcare sector (Karim, Sandu, \& Gide, 2020) .

- Authority struggle in Al adoption and the lack of investment in Al applications are some of the (Nazer \& Tuffaha, 2017) major factors for Al dilemma.

- Still the health care providers in Jordan are not fully ready to be Al users, they are likely to show worry and insecurity about the e-service and feel less hopeful and innovative about the technology.

- The private health sector and the public health sector can make noteworthy development in developing Al push through its health industry association (Karim, Sandu, \& Gide, 2020) .

- In order to endorse acceptance of Al, all healthcare providers in Jordan should offer their stakeholders with step-by-step demonstrations which demonstrate the steps for using Al on the health sector (Karim, Sandu, \& Gide, 2020) .

- This paper has identified that security and privacy satisfaction is the vital factor to take into attention by health stakeholders before adopting Al. 
- The lack of trust in health \& safety lead to the failure of Al in Jordan healthcare system (Karim, Sandu, \& Gide, 2020).

- The effect of Artificial Intelligence (AI) adoption is an argumentative point with the researcher. Young Jordanian people are more likely to be adopters of Al than aged people (Yu, Beam \& Kohane, 2018).

- Jordan Government can play a vital role to advance business activities for Al adoption in health sector.

\subsection{The Fields of Al Applications in Jordan Healthcare}

This section also has valued some additional key findings which are as below-

Client Insights: Al can gain from the information, foresee fates states and follow up on the produced bits of knowledge. With the union of Al and Data Analytics/Business Intelligence, Al empowers human services organizations to more readily connect with the clients.

Robotized Data and Document Management: Daily activities create a colossal measure of information and documentation that can expand the measure of time human services experts spend on managerial undertakings. Artificial intelligence can oversee information and archives precisely and appropriately allowing for human services experts to concentrate on esteem included undertakings and patients.

Patients Diagnosis: With advancements, for example, Google Cloud Intelligence Video, soon AI will have the option to help HCPs in therapeutic picture investigation, perceiving for instance malignancy through an X-Ray. Among numerous different ways, filtering Electronic Health Records is additionally another way Al can help with the analysis of patients (Petryni, 2016).

Medicines Effectiveness: Companies are taking a gander at utilizing Al to foresee how singular patients are going to react to explicit medications. A healthcare provider in a joint effort with other organizations can utilize $\mathrm{Al}$ and genome information to anticipate the adequacy of malignant growth medicines (Maddox, Rumsfeld \& Payne, 2019).

Medication Discovery: Al looks into is driving and quickening new logical disclosures. Protein collapsing is key in getting illnesses and medications and has been a significant test for mainstream researchers as it tends to be exorbitant and tedious. Al can empower to be progressively proficient in the medication disclosure process (Manyika \& Sneader, 2018).

Human Augmentation: Al can be utilized to increase human abilities. This field opens a wide scope of cutting-edge applications at the individual level yet additionally hierarchical level where the market could see a split between Al-empowered organizations and the others. Advances in Al is changing the human services industry and patient consideration. Nonetheless, past the innovation development, there are yet numerous difficulties to defeat before we can completely use the capability of Al - Ethics being one of the most basic (Yu, Beam \& Kohane, 2018).

\section{Discussion}

Artificial Intelligence (Al) is a joint account on potential use in paediatric stem and invulnerable cell treatments and regenerative medication (Jiang et al., 2017). It is a profoundly attractive scholastic field of numerous present fields of studies (Petryni, 2016). The focal objectives of Al examine are thinking, information, arranging, learning, common language preparing (correspondence), discernment and the capacity to move and control objects (Manyika \& Sneader, 2018). 
Al has been the subject of huge, good faith however has additionally endured dazzling difficulties (Manyika \& Sneader, 2018). These keen machines could analyse the entire genome and separate the resistant particularities of individual patient's sickness in only minutes and make the treatment that is altered to patient's hereditary explicitness and insusceptible framework capacity. Al strategies could be utilized for improvement of clinical preliminaries of creative immature microorganism and quality treatments in paediatric patients by exact arranging of medicines, foreseeing clinical results, streamlining enrolment and maintenance of patients, gaining from input information, and applying to new information, in this manner bringing down their unpredictability and expenses (Manyika \& Sneader, 2018).

Presently, there are huge quantities of progressing ventures concerning the Al usage in numerous zones of science, pharmaceutical and medicinal services (Petryni, 2016). To structure tolerant physical attributes dependent on DNA and to couple the total genomes with full body examines and nitty gritty restorative registration (Manyika \& Sneader, 2018). To combine square chain innovation with the latest Al advancements to quicken the advancement in biomedical research and wellbeing (Manyika \& Sneader, 2018).

To help the improvement of well-educated clinical preliminaries, joint effort between Al experts and clinicians is required to enable subjective speculations to take on a quantitative measurement (Manyika \& Sneader, 2018). Al has become a significant region of research in health-related fields. The utilization of computational models dependent on neural systems for complex tissue designing applications and the forecast of tissue building results, the utilization of robot based quick prototyping framework for platform creation, particularly in musculoskeletal applications and the robotized cell handling automated frameworks (Petryni, 2016) .

It is normal that Al robotization went with utilizing mechanical technology can reform the ordinary tissue designing and regenerative medication treatments and bringing new trust in patients. Each choice made prompts an encounter which is chronicled and added to the data that is put away to assist settle on with bettering choices later on.

\section{Conclusion}

This study principally talks about Al existence in Jordan healthcare system. But Al and its related technologies are still in its preliminary stage in Jordan because of many limitations. The researchers have provided some probable and recommendations. For accomplishing the best possible outcome from the $\mathrm{Al}$, the researchers have offered below recommendations.

- Jordanian all health care providers should improve their system more user friendly and they should need to examine in building the IT infrastructure to ensure that the services will be user friendly in the design as well.

- Jordan Government must concentrate most on acts, policy, and procedures for ICT.

- Regular launch of digital forensic workshop for examination

- Distribution and understanding to developed countries' proficiency in relation to implementation of a complete legal guideline for adoption of Al.

- Dependable, accurate and present evidence are always required for Al on judicial requirements.

- Jordan needs a modernised education system that can bring educators and learners with skills and knowledge to obtain Al and improve advancement and distinctiveness and overall ICT experience. 
- Jordan should be self-governing from both the educational institutions and government spokespersons

- Jordan Government should provide a strong legal framework for Al and good practice the proper National ICT security policy.

- Launch good practice guidelines against cybercrime.

- Establish digital forensic laboratory for proper examination and finding the cybercrimes.

- To do internal and external training to the health educators and learners on ICT misconduct inquiry.

- Jordanian health and ICT experts should develop own software for banking systems more frequently

- Virtual transaction must have validity and privacy.

- The smooth connectivity of the internet and network improvements of Jordan is expected to improve.

\section{References}

Abdel-Razeq, H., Attiga, F., \& Mansour, A. (2015). Cancer care in Jordan. Hematology/oncology and stem cell therapy, 8(2), 64-70. https://www.sciencedirect.com/science/article/pii/S1658387615000230

Al-Alami, H., Hadi, A., \& Al-Bahadili, H. (2017, December). Vulnerability scanning of loT devices in Jordan using Shodan. In 2017 2nd International Conference on the Applications of Information Technology in Developing Renewable Energy Processes \& Systems (IT-DREPS) (pp. 1-6). IEEE. https://ieeexplore.ieee.org/abstract/document/8277814/

Al-Hawary, S. I. S. (2012). Health care services quality at private hospitals, from patients' perspective: A comparative study between Jordan and Saudi Arabia. African Journal of Business Management, 6(22), 6516-6529. https://academicjournals.org/journal/AJBM/article-abstract/E3A5C4330865

Bani-Salameh, H., Al-Qawaqneh, M., \& Taamneh, S. (2021). Investigating the Adoption of Big Data Management in Healthcare in Jordan. Data, 6(2), 16. https://www.mdpi.com/989504

Barr, A., \& Feigenbaum, E. A. (Eds.). (2014). The Handbook of Artificial Intelligence: Volume 2 (Vol. 2). ButterworthHeinemann. https://www.amazon.com/Handbook-Artificial-Intelligence-2/dp/086576090X

Goodman, K., Zandi, D., Reis, A., \& Vayena, E. (2020). Balancing risks and benefits of artificial intelligence in the health sector. Bulletin of the World Health Organization, 98(4), 230. https://www.ncbi.nlm.nih.gov/pmc/articles/PMC7133475/

Hernández-Orallo, J., \& Vold, K. (2019, January). Al extenders: the ethical and societal implications of humans cognitively extended by AI. In Proceedings of the 2019 AAAI/ACM Conference on Al, Ethics, and Society (pp. 507-513). https://dl.acm.org/doi/abs/10.1145/3306618.3314238

Ishaqat, D. (2021). Jordan: social media and social change opportunities and threats. In Social Media Impacts on Conflict and Democracy (pp. 121-130). Routledge.

Jiang, F., Jiang, Y., Zhi, H., Dong, Y., Li, H., Ma, S., ... \& Wang, Y. (2017). Artificial intelligence in healthcare: past, present, and future. Stroke and vascular neurology, 2(4). https://svn.bmj.com/content/2/4/230.abstract

Karim, S., Sandu, N., \& Gide, E. (2020). A study to analyse the impact of artificial intelligence (Al) in transforming Australian healthcare. Global Journal of Information Technology: Emerging Technologies, 10(1), 01-11. https://un-pub.eu/ojs/index.php/gjit/article/view/4533

Leslie, D. (2019). Raging robots, hapless humans: the Al dystopia. Nature, 574(7776), 32-34. https://go.gale.com/ps/i.do?id=GALE\%7CA601579001\&sid=googleScholar\&v=2.1\&it=r\&linkaccess=abs\& $\underline{\mathrm{issn}=00280836 \& \mathrm{p}=\mathrm{AONE} \& \mathrm{sw}=\mathrm{w}}$

Maddox, T. M., Rumsfeld, J. S., \& Payne, P. R. (2019). Questions for artificial intelligence in health care. Jama, 321(1), 31-32. https://jamanetwork.com/journals/jama/article-abstract/2718456 
Manyika, J., \& Sneader, K. (2018). Al, automation, and the future of work: Ten things to solve for. http://dln.jaipuria.ac.in:8080/jspui/bitstream/123456789/1335/1/MGI-Briefing-Note-Al-automationand-the-future-of-work June2018.pdf

Mitchell, R., Michalski, J., \& Carbonell, T. (2013). An artificial intelligence approaches. https://link.springer.com/content/pdf/10.1007/978-3-662-12405-5.pdf

Mohammad, H., Almarabeh, T., \& Ali, A. A. (2009). E-government in Jordan. European Journal of Scientific Research, 35(2),

188-197. https://citeseerx.ist.psu.edu/viewdoc/download?doi=10.1.1.1060.8258\&rep=rep1\&type=pdf

Murphy, R. R. (2019). Introduction to Al robotics. MIT press. https://mitpress.mit.edu/books/introduction-airobotics

Nazer, L. H., \& Tuffaha, H. (2017). Health care and pharmacy practice in Jordan. The Canadian journal of hospital pharmacy, 70(2), 150. https://www.ncbi.nlm.nih.gov/pmc/articles/pmc5407425/

Pakurár, M., Haddad, H., Nagy, J., Popp, J., \& Oláh, J. (2019). The service quality dimensions that affect customer satisfaction in the Jordanian banking sector. Sustainability, 11(4), 1113. https://www.mdpi.com/415378

Petryni, M. (2016). Small Business Difference between Strategic \& Operational Objectives. https://auorgcomm.wordpress.com/2016/11/02/the-human-relations-behind-apple/

Robins, P. (2019). A history of Jordan. Cambridge University Press. t.ly/YYKS

Shortliffe, E. (Ed.). (2012). Computer-based medical consultations: MYCIN (Vol. 2). Elsevier. https://ci.nii.ac.jp/naid/10006722694/

Yu, K. H., Beam, A. L., \& Kohane, I. S. (2018). Artificial intelligence in healthcare. Nature biomedical engineering, 2(10), 719-731. https://www.nature.com/articles/s41551-018-0305-z

Zaid Alkilani, S., Jupp, J., \& Sawhney, A. (2013). Issues of construction health and safety in developing countries: a case of Jordan. Australasian Journal of Construction Economics and Building, The, 13(3), 141-156. https://search.informit.org/doi/abs/10.3316/informit.604959233854855 